\title{
To the question of development single-industry towns through the realization of economic interests and the formation of the stability of enterprises
}

\author{
Nailya Khadasevich $^{1}$ [0000-0002-7908-618X], Marina Imamverdieva ${ }^{1 *}{ }^{* 0000-0001-5226-2668], ~ N a t a l i y a ~}$

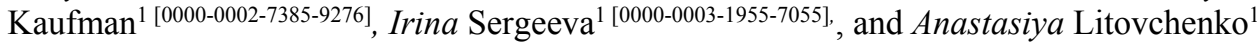 \\ [0000-0002-3692-7030]
}

${ }^{1}$ Surgut State University, 628412, Lenin Ave., Surgut, Russia

\begin{abstract}
Identification and implementation of the economic interests of the fuel and energy sector enterprises is an important stage in the formation of a strategy for crisis management of the region. The complexity and multidimensional nature of the concept of «Regional Crisis Management», as well as its exposure to a complex of factors and conditions, does not allow us to develop a unified approach to balance the interests of all subjects. The triad of elements «region-industry-enterprise» are not only independent representatives of interests, but also interdependent categories. The importance of improving the efficiency of interaction between all carriers of economic interests increases, since their structural expression and hierarchy will allow identifying points of intersection of interests and, consequently, increasing the efficiency of their functioning.
\end{abstract}

Keywords: stability of enterprises, crisis management, economic entities, economic interests, single-industry towns.

\section{Introduction}

The main goal of anti-crisis management, as a type of management activity, is to overcome or prevent the crisis, minimize the negative consequences, by making rational and effective management decisions. Crisis management is considered not only within enterprises, but also at the level of the state and regions.

Anti-crisis management of single-industry towns is a complex and multidimensional type of anti-crisis activity, since in this case; the peculiarities of the functioning of not one organization, but a group of enterprises should be taken into account [1].

The crisis state of the region, most of the cities of which operate in a certain industry, is characterized by the following trends:

- reduction in the number of jobs, the growth of the unemployed;

- decrease in the gross regional product in dynamics compared to previous years;

- lower average wages;

\footnotetext{
${ }^{*}$ Corresponding author: $\underline{1 \text { mi130401@gmail.com }}$
} 
- reduction of the minimum wage and the subsistence minimum;

- deterioration of the quality of life of the population:

- reducing the efficiency of the region's underlying industry.

To date, there is no single approach to regional crisis management, as the management of the region covers a wide range of issues.

\section{Materials and methods}

In the study, the authors encountered the following methodological limitations: the lack of sufficient empirical information to form a model of matching interests.

Based on the system analysis, it becomes possible to consider the process of realization of economic interests by a set of carriers.

According to the authors, content analysis allows a comprehensive approach to the research process and form appropriate conclusions.

An extensive and comprehensive analysis of the categories of this work, conducted by domestic and foreign scientists, does not reduce the degree of relevance in a particular field of economic science. Now there is no universal and at the same time effective model of coordination of economic interests in the process of crisis management. The considered mechanism of realization of economic interests in the context of anti-crisis management allows making more rational and practically effective management decisions and measures to eliminate crisis phenomena.

\section{Results}

There is a complexity of the anti-crisis management of the region because it is necessary to analyze all the main aspects of the operation of the enterprise: social, economic, political, environmental, etc.

In this regard, many regions are in a state of anticipatory anti-crisis management, which leads to a decrease in the positive dynamics of indicators [2].

The main goal of regional crisis management can be defined as the achievement of sustainable development of the region. This goal can be achieved through an integrated approach to the development of the region, which involves the implementation of various regional programs, their constant analysis and elimination of the weakest points.

It is important to note that not only the specifics of the activity and the industry affect the anti-crisis management, but also the policy in the state and the region, competitors, currency and legislative regulation have a significant impact.

The anti-crisis management of the region has its own characteristics in comparison with the anti-crisis management of the enterprise [3]. The company has a homogeneous field of activity or similar areas of operation. The region is a more complex object, as it includes different areas of activity. It is possible to single out a larger, leading direction, but ignoring other industries can lead to their depreciation or decrease in productivity.

In the literature, in most cases, more attention is paid to the anti-crisis management of the enterprise or the state. The region, as a managed unit, is considered much less often.

The ultimate goal of anti-crisis management of regional development is to improve the level and quality of life of the population of the region, based on the support of systemforming industries and industries and the promotion of economic growth.

"When choosing a particular form of regional crisis management, it is necessary to take into account not only the macroeconomic indicators that led to the emergence of the crisis, but also the factors and conditions that can strengthen or, on the contrary, minimize the causes of regional crises at the regional level» [4, p. 35]. 
Inefficient regional management leads to the absence of an anti-crisis strategy in the region [5]. The anti-crisis strategy of the region implies a set of measures that will prevent or reduce the impact of the crisis on all aspects of the region's activities: social, economic, managerial, resource, educational, and innovative.

An effective anti-crisis strategy for the development of the region should reflect the» growth points « (promising areas) of the region, which are the basis for its development. The definition of «growth points» allows the region to develop and implement new areas of activity, with the effective functioning of conservative areas (the resource aspect).

The anti-crisis strategy of the region should be developed not only taking into account the resource and geopolitical features of the region, but also taking into account innovative, relevant areas of development that can correct the negative impact of the crisis on the economy.

According to N. V. Danilova, «the indicator of the effectiveness of the implemented system of anti-crisis management of the region's economy is the dynamics of the number of financially insolvent enterprises, enterprises in financial crisis, the methods and forms of state regulation of the institution of bankruptcy and financial recovery» [6, p. 33].

The region as a management unit plays an important role in the formation and development of the economy of the entire state. The region is an independent subject of economic relations and, accordingly, has its own economic interests.

Each individual region has its own specific characteristics and properties. As a rule, this difference is due to territorial, political, economic, resource and social characteristics. Therefore, it is not possible to develop a single management strategy for all regions. It is necessary to take into account regional peculiarities and because of this to develop a strategy for the development of the subject [7]. However, despite this, regions can also have common goals and interests, which are expressed in the achievement of performance indicators not of an individual subject, but of the entire state.

The effectiveness of the region's activities depends on the consistency of: the economic interests of the region and the state as a whole, the economic interests of the profile industry and the region, the economic interests of the enterprises of the profile industry and the region.

In the case of considering the region as a carrier of economic interests, it is necessary to take into account that the region is a representative of the interests and economic entities that are located and operate in it.

This fact makes it difficult to realize the economic interests of the region, since it is not always possible to implement the interests of all economic entities equally effectively and rationally [8]. In turn, the economic entities have a significant impact on the region and are the main economic force.

«Economic interests in the region are manifested in a vertical cross-section, as links with federal structures, municipalities and economic entities within the region, forming a chain: federation-region-municipality-economic entities, as well as horizontal links, manifested in the form of interaction between other regions and other entities within the federation and beyond» $[9$, p. 53].

The region exists as a separate economic unit, but at the same time, the region is also one of the subjects of the state. Consequently, the efficiency of a country's economy depends on the effective functioning of all its regions [10].

Due to the territorial features of Russia, namely its large extent, it is impossible for each region to develop a single strategy for the implementation of economic interests. This is because the region is a complex structure [11]. For example, the economic interests of a resource-producing region and, conversely, a region where there is no extraction of any raw materials are different and, perhaps, even opposite. In the first case, the main carrier of the 
economic interests of the region will be industry, in the second case; industry will no longer be the prevailing carrier of economic interests due to its absence in this subject [12].

«Any industry in the region is represented by economic entities-enterprises. Consequently, there is a triad of regional economic interests: region-industry-enterprise. Economic interests in it have a single key object-resource. The distribution and redistribution of financial, material, labor, intellectual, and information resources lies in the content of various group interests» [13].

The interdependence of such categories as region, industry and enterprise, as already mentioned above, is based on the resources, raw materials of this region [14].

In order to coordinate the economic interests of the region, its leading industry and the enterprises that directly carry out this activity, it is necessary to determine the points of contact, thanks to which their purposeful development can be ensured and the ways to implement their interests can be coordinated [15].

The common interests of the region, its leading industry and groups of enterprises in this industry can be expressed in the following points [16]:

1. Improving the performance of the leading industry leads to an increase in the gross regional product and ensures the sustainable development of the region as a subject of the state.

2. The development of the industry contributes to the growth of the number of enterprises and, as a result, the growth of jobs. Providing the population with jobs and reducing the unemployment rate is one of the priorities of the regional policy.

3. The effective functioning of the leading industry enterprises ensures the state's interest in the development of this region by investing in the development of the leading industry.

To determine the leading industry in the region, it is necessary to analyze the indicators of the gross regional product and determine the products of which industry occupy the largest share in the final indicator [17].

To determine the group of city-forming enterprises, it is necessary to calculate the average number of employees for the period and to correlate the number of employees in a particular industry to the number of the working population of a given region [18].

It is also necessary to estimate the average salary of the city-forming enterprises and correlate it with the average salary of the region.

The specifics of the implementation of regional economic interests is to identify the most important, resource-intensive industries, the crisis state of which can lead to a significant negative impact on the region. It is impossible to implement crisis management equally effectively in the territory and in the areas of the entire region, due to the large number of representatives of economic interests.

The realization of economic interests is primarily based on the characteristics of the bearer of this interest. As noted earlier, each individual entity is a collection of other entities, which, in turn, are also representatives of economic interests. The triad of economic interests of the state can look like this: «state-region-enterprise».

«The system of national economic interests, which is a subsystem of world economic interests - is a set of economic relations for the formation and movement of national conditions of social production and the realization of its goals» $[19, \mathrm{p} .2]$.

Consequently, the national interests of Russia are expressed by the totality of the economic interests of various spheres of production. Since it is impossible to achieve the goals of all spheres in an equilibrium value, it is necessary to analyze the structure of GDP and determine the most important directions. On the other hand, there is a contradiction in this issue - since in the case of choosing the most significant industries in the GDP structure, the possibility of realizing the interests of new, promising, innovative directions is not possible. This is the complexity of implementing national interests, since the 
selection of priority areas and the analysis of their development prospects is a time consuming and multi-factorial process.

Taken together of Russia's national economic interests, the implementation of the economic interests of the fuel and energy sector is of the utmost importance. This fact is due to the size of its specific weight in the structure of the national economy of the Russian Federation.

The interaction of regional fuel and energy companies with national interests can be expressed in the following provisions:

1. Coordination of export, energy, and investment policy indicators with actual fuel and energy sector indicators.

2. The contribution of fuel and energy companies to the budget of the regions and the state.

3. Development of related fuel and energy industries.

4. Development of subjects in the Russian Federation taking into account the development of the fuel and energy sector.

5. Reducing the unemployment rate, providing the population with jobs.

6. Development of the state within the framework of the development of the industry, a significant role in the global market of fuel and energy resources.

7. Economically, the interests of the fuel and energy sector enterprises should be subordinated to the interests of the state, since these enterprises are budget forming.

As a rule, a large number of city-forming enterprises characterizes the fuel and energy complex in the regions of the Russian Federation. This fact leads to a high degree of importance of rapid and effective adaptation of fuel and energy companies in the crisis or in the post-crisis period [20].

The untimely restoration or liquidation of such enterprises due to the crisis conditions leads to violations and imbalances not only in the economy of the region, but also in the economy of the state [21].

«The regional component of the effect of the fuel and energy complex consists, on the one hand, in satisfying the population of the region in the services of the fuel and energy complex of the required volume and quality, on the other hand, in ensuring the economic interests of regional power structures in the sphere of the fuel and energy complex» [21, $\mathrm{p}$. 38].

The main task of regional fuel and energy companies is to satisfy economic interests not only at the regional level, but also at the state and international levels. The strategy of targeting different markets: regional, state and international, allows the industry to provide investment and innovation potential and «implement not a passive (based on macroeconomic trends), but an active scenario of regional development» [23].

The common interests of the region and the state in the context of the fuel and energy sector are expressed in achieving such a position of the fuel and energy sector, in which the progress of society can be ensured (effective use of human resources, development of human potential), increasing revenues (regional and state, development of export potential), reducing costs, developing interconnected industries through the fuel and energy sector, developing an innovative and scientific approach to production (the demand for scientific results in the fuel and energy sector).

The ratio of regional and state economic interests in the context of the fuel and energy sector depends on the state of the region and its importance, role at the country level. Finding a compromise, synergy of economic interests becomes the basis for determining the directions of development of the state and the region.

The economic interests of the region are manifested in improving the quality characteristics of the fuel and energy complex, which are based on the effective and rational use of the resource potential. 
According to the Energy Strategy of Russia until 2035, «The most important provision of the ES-2035 in the field of increasing the economic efficiency of the fuel and energy complex is a departure from the target of maximizing exclusively budget revenues from the functioning of the fuel and energy complex of Russia. The main goal is to maximize the overall economic effect, taking into account the indirect multiplicative effects of the functioning of the Russian fuel and energy complex. At the same time, the economic interests of the fuel and energy sector enterprises are considered in conjunction with the tasks of the state budget» [24].

The implementation of crisis management in the context of strategic planning in the Energy Strategy of Russia until 2035 is not considered, but this issue will be considered as part of the annual monitoring of the implementation of the Strategy with the development of appropriate recommendations.

The main task of the fuel and energy sector enterprises in the system of anti-crisis management is to determine the ways and directions of implementing their interests in the conditions of transformations caused by the crisis.

The consequences or transformations of the crisis can be new economic relations, the restructuring of relations between subjects, the development of an innovative approach. In this regard, enterprises need to be able to adapt to new conditions, adjust their activities, and determine current approaches to the management process.

There is a complexity and multi-factor nature of the anti-crisis management of regional fuel and energy enterprises because regional anti-crisis management is a specific form of activity and it is based on both general principles and specific features that are characteristic only for management in the context of the region.

In the context of crisis management, the most important task at the level of regional fuel and energy sectors is to ensure the continuity, consistency and rationality of production, as well as the development of the industry or the preservation of regulatory indicators (depending on the degree of the crisis). However, in the practical activities and real functioning of regional fuel and energy companies, the implementation of the abovementioned task is complicated by the discrepancy between the economic interests of various subjects of the region.

It is important to note that the region, industry and enterprise are not the sole expression of economic interests, but are represented as composite carriers.

Each of the triad elements of the region: region-industry-enterprise has its own carriers of economic interests in crisis management. Because the concept of a region is a complex category, when identifying economic interests and their implementation in the process of crisis management, it is necessary to determine all the categories that bear economic interests, as well as to identify, in fact, the interests themselves, as well as to determine the method of their implementation. At the same time, the difficulty lies in finding an optimal and more effective way to implement economic interests, in which the interests of each carrier will be satisfied [25].

The activities of each of the subjects of economic interests: the region, industry and enterprise, are aimed at realizing the possibility of full ownership and distribution of the main resource of the region and obtaining a positive economic effect. Each of the subjects can realize their economic interests only through this resource. Consequently, regional economic interests can be concentrated around a single concept of «resources».

Based on the above, it can be concluded that the inconsistency of the economic interests of the region in the process of crisis management can be expressed in a common goal: the ownership and disposal of the resource. Despite the common goal, some ways of implementation and the desired benefits will be different. In some cases, the economic interests of different subjects coincide, but the benefits are different for each. 
A comprehensive and systematic analysis of regional economic interests should be aimed at finding points of contact between different subjects and their equilibrium way out of the state of crisis. Then it is necessary to analyze the ways of implementing the data and interests and draw a conclusion about the consistency of the ways of some subjects with the methods of implementing the interests of other subjects.

Building a model of coordination of economic interests in the process of anti-crisis management is the basis for stabilizing the activity of the subject, for restoring its normal functioning in the new conditions.

For general modeling of the mechanism of coordination of economic interests of regional fuel and energy companies in the process of anti-crisis management, it is necessary to assign a certain designation to each bearer of interests:

S1 - state; S2 - region; S3 - fuel and energy companies; S4 - employees; S5 shareholders; S6 - counterparties.

This list is not exhaustive, in the process of development and formation of new economic relations and the establishment of new relations between subjects, new subjects appear-carriers of economic interests.

Each subject has its own individual economic interests (I), which are manifested at a certain point in time, in this case in the process of crisis management (tc) and with a certain resource potential of each carrier (p).

When forming a model of coordination of economic interests, it is necessary to bring the interests of all subjects to a state of equality:

$$
\mathrm{S} 1(\mathrm{I})=\mathrm{S} 2(\mathrm{I})=\mathrm{S} 3(\mathrm{I})=\mathrm{S} 4(\mathrm{I})=\mathrm{S} 5(\mathrm{I})=\mathrm{S} 6(\mathrm{I})
$$

To form such an agreement, it is necessary to determine a set of optimally correct solutions that will satisfy the interests of all subjects.

The optimal set of decisions (Ropt), most often, is a certain set of actions (D) that bring the interests of different subjects into a state of balance.

Therefore, the optimal set of solutions is equal to a certain set of actions. In turn, this relationship is formed by the state of consistency of the interests of all subjects of the Ssp. In the form of a formula, this equality can be expressed as follows:

$$
\text { Ropt=A (D) = C S1 (I) = S2 (I) = S3 (I) = S4 (I) = S5 (I) = S6 (I) }
$$

It is possible to determine a set of optimal solutions by diagnosing the consistency of economic interests and identifying their mismatch. Therefore, it is necessary to determine the determinants that lead to balance. It is also necessary to determine the factors of impact on enterprises, in this case-the state of crisis.

The moment of determining the alignment and mismatch of economic interests is very important, as it is the basis for further modeling the process of alignment of interests. It is necessary to determine the points of contact of the interests of the subjects, which in the graphical version are displayed as points of intersection. This intersection allows you to find the categories that determine the points of agreement of economic interests, and the exact definition of the intersection points allows you to build a line of interests of each subject with the condition of mandatory intersection at the point of «consistency». It is important to note that there may be several such points, but the main condition is the intersection of the interests of all subjects at a given point.

A certain point, which is the intersection of all other interests - is a point of agreement. That is, the interests of different subjects, different in nature, in their indicators and in their goal setting, have a certain consensus, a certain point, which can be determined to build a vector of stabilization of interests. 
Theoretically, it is possible to determine this point by analyzing the interests and finding the so-called similar or subordinate hierarchies of the built interests. It is important to note that the graph should be static, i.e. considered under certain conditions.

The interests of all subjects tend to the maximum in the mathematical sense, and in the economic sense-to the maximum satisfaction of their own interests. Based on this, a function is formed, which is represented as follows:

$$
\left\{\begin{array}{c}
\mathrm{X} \in \mathrm{Ropt}, \mathrm{Rmin} \geq \mathrm{Ropt} \geq \mathrm{Rmax} \\
\mathrm{A}(\mathrm{D})=\mathrm{Cs}
\end{array}\right.
$$

According to this system, the point $\mathrm{X}$ belongs to the domain of optimal solutions, which has restrictions in the form of maximum and minimum values. I.e., the value of the point of contact of interests cannot go beyond the optimal set of solutions.

The optimal set of solutions creates such conditions under which the interests of the subjects touch at a certain point (at this point, a conflict of interests is excluded), and the point X can only be located within certain limits of the optimal set of solutions.

The above equation is descriptive, it does not reflect the specific features of the field of activity and the period, and it describes the basis for achieving a balance of economic interests of the subjects.

In the context of this study, the model of coordination of the economic interests of regional enterprises of the fuel and energy complex in the context of crisis management is considered.

The formation of a model of coordination of interests and interaction of all economic entities of the fuel and energy sector in the context of crisis management depends on the following factors

- territorial characteristics of the region;

- industry development prospects;

- the importance and significance of the regional fuel and energy sector in the total volume of resource extraction in the country;

- the volume of tax payments and insurance premiums as a budget-forming factor;

- support of the industry from the region and the state;

- the lack of strategic interests of the company's management personnel in relation to the enterprise and the industry.

The carriers of the interests of regional fuel and energy companies are shareholders, employees, fuel and energy companies, contractors of enterprises, the region represented by the authorities, the state as an interested person in the development of the industry.

It should be noted that the interests of all subjects are interdependent, i.e. as one subject expresses certain interests in relation to another subject, thereby forming economic relations, so another subject is the bearer of economic interests in relation to the subject.

Defining these relationships and establishing economic interests, it is important to determine not only the nature and main goals of the subject, but also how to implement them.

\section{Discussion}

The model of coordinating the economic interests of regional fuel and energy companies in the context of crisis management should be based on an individual approach to the development of the fuel and energy sector in each region of Russia. The basis for this is: the effective demand of the population for fuel and energy resources, the balance of the quality of the products provided and the set price for buyers and contractors, meeting the needs of the population and the state in the quantity of products. 
The model of coordination of economic interests, as a complex system, can contain several levels of interaction, which, in turn, are characterized by a certain set of conditions and factors. When analyzing the crisis of an enterprise, there may be a situation of mismatch or, conversely, coordination of interests. As mentioned above, the process of realization of economic interests can be accurately determined only in the case of a state of their coherence. That is, the model of coordination of economic interests is updated in the case of well-defined properties of the system and subjects. In addition, an important role is played by the crisis of an enterprise or industry, as a factor that has both an external and internal impact.

The model of coordination of economic interests of different subjects during the crisis should reflect the need to concentrate the interests of all subjects on reducing the negative impact of the crisis. The interests of the subjects cannot be expressed in quantitative terms, but it is possible to determine those financial categories that express the interests of the majority of subjects in a crisis.

The profit and value of the enterprise are the main categories of the functioning of the enterprise, which reflect the financial condition of the organization's activities. The choice of these indicators is justified by the fact that they concentrate the goal setting, and, consequently, the interests of all the above-mentioned subjects.

Since these indicators are categories on which the economic interests of all subjects are concentrated, it is necessary to analyze their relationship by means of the Spearman correlation coefficient. An assessment of the degree of close connection between these indicators in crisis conditions will allow us to assess their relationship. This relationship will allow you to assess how the change in profit affects the change in the value of the organization. Profit reflects the interests of employees, regional authorities, the state and contractors, and the value of the enterprise reflects the interests of shareholders.

To assess the degree of inconsistency or consistency, it is necessary to analyze the standard deviation and the coefficient of variation of the indicators.

The coefficient of variation shows the uniformity or heterogeneity of a set of indicators. Some scientists characterize the heterogeneity of the structure as a process of mismatch of interests. In the above material, it is the standard deviation and the coefficient of variation of the ratio of profit to the value of the enterprise that is considered. The calculation of these indicators separately for each category does not allow us to analyze the process of their coordination and mismatch.

When calculating them, it is necessary to evaluate the real process of the enterprise's functioning and determine the ways to resolve conflicts of interests, conditions, forms, methods and tools of coordination (Table 1).

The lack of a clear definition of forms, methods and tools for coordinating economic interests does not allow enterprises to reduce the negative consequences of the crisis by balancing the economic interests of the subjects. In turn, a timely analysis and diagnosis of economic interests, as well as the process of their coordination and misalignment, allows us to determine the optimal set of solutions that, in the context of crisis management, concentrates the resource and time potential of the organization on the elimination of crisis phenomena.

Based on the above, the model of coordination of economic interests can be represented as follows (Fig.). 
Table 1. The process of coordinating the economic interests of the subjects.

\begin{tabular}{|l|l|}
\hline $\begin{array}{l}\text { Ways } \\
\text { to resolve } \\
\text { conflicts of } \\
\text { economic } \\
\text { interests }\end{array}$ & $\begin{array}{l}\text { 1.Defining the main goal in a crisis - the maximum conservation of } \\
\text { resources and cost reduction. } \\
\text { 2. Identification of more significant areas of activity that do not contradict } \\
\text { the interests of the subjects. } \\
\text { 3. Localization of crisis phenomena, prevention of increasing the radius of } \\
\text { coverage of the crisis. }\end{array}$ \\
\hline $\begin{array}{l}\text { Terms of } \\
\text { agreement } \\
\text { of interests }\end{array}$ & $\begin{array}{l}\text { 1. Ensuring the centralization of activities and management. } \\
\text { 2.Definition of horizontal relations between the subjects, for the primary } \\
\text { coordination of these interests, and after-interests according to the degree of } \\
\text { hierarchy. }\end{array}$ \\
\hline $\begin{array}{l}\text { Approval } \\
\text { forms }\end{array}$ & $\begin{array}{l}\text { 1. Official - based on the regulatory framework (which is poorly developed } \\
\text { in the field of the implementation of economic interests) } \\
\text { 2. Informal - based on the subjective attitude, objective analysis of data, and } \\
\text { the degree of importance of the subjects. }\end{array}$ \\
\hline $\begin{array}{l}\text { Matching } \\
\text { methods }\end{array}$ & $\begin{array}{l}\text { 1. Analysis of points of intersection of interests, construction of a vector of } \\
\text { development of interests from this point. } \\
\text { 2. Elimination of contradictions by concentrating the interests of all subjects } \\
\text { on the main interests in a crisis. }\end{array}$ \\
\hline $\begin{array}{l}\text { Approval } \\
\text { tools }\end{array}$ & $\begin{array}{l}\text { 1.Definition and planning of indicators of economic interests of regional } \\
\text { enterprises in the context of state policy. } \\
\text { 2. The formulation of precise indicators are based on which it is possible to } \\
\text { speak about the state of crisis in the enterprise. }\end{array}$ \\
\hline
\end{tabular}

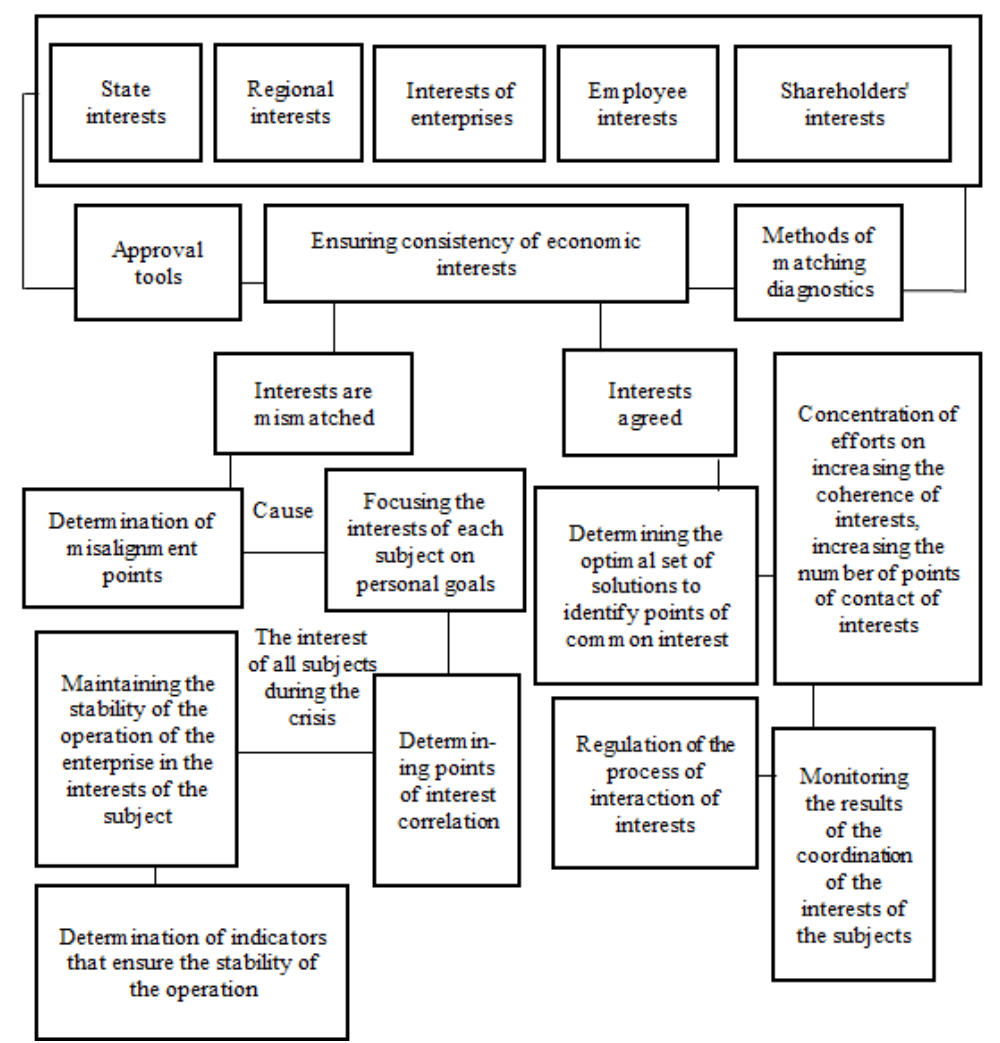

Fig. Model of coordination of economic interests in the process of crisis management. 
The interests of all subjects of regional fuel and energy companies in the process of crisis management are focused on the preservation of financial indicators, as this serves as the basis for the implementation of the economic interests of all subjects.

The instruments of coordination of economic interests are: the state-sanctions, tax policy, preferential conditions for enterprises in a crisis, price stabilization; the region-support for enterprises in a crisis; fuel and energy companies-preservation of wages and jobs of employees, preservation of production volumes; employees-performance of official duties in full; contractors-preferential payment terms; shareholders-acceptance of the cancellation of dividend payments in order to form reserve funds.

Methods of diagnostics of coordination of economic interests of regional enterprises of the fuel and energy complex include: methods of correlation coefficients as a way of diagnostics of closeness of connection between indicators, coefficient of variation as a way of assessment of the population (homogeneous, heterogeneous), coefficient of concordance as a way of assessment of coordination of opinion of experts (this method is applicable in the case when a group of experts-specialists in this industry is formed to assess consistency). In addition, in this case, the method of expert assessments can be applied, which is not only an element of calculating the concordance coefficient, but also an independent method. This method consists in ranking the opinions of experts of the economic interests of the subjects, and because of this, the points of intersection of interests are determined.

When building a model, it is important to determine the interests of the subjects and build relationships between the subjects, which are economic relations. Creating conditions for the effective implementation of economic relations makes it possible to purposefully eliminate the crisis, localize the negative consequences, and develop a development trajectory taking into account the interests of different subjects.

\section{References}

1. K. A. Borisovskaya, Foreign economic supranational and national interests: structure and priorities (2018)

2. V. G. Frolov, Y. A. Sidorenko, D. I. Kaminchenko, Harmonization of interests of stakeholders in the context of Industry 4.0, EurAsian Journal of Bio Sciences, 14, 66996704 (2020)

3. A. Greenfield, Against the smart city (The city is here for you to use Book 1 (Kindle Edition, 153, 2013)

4. V. V. Melnikov, Public and private interests in the regulation of economic orders in single-industry towns of Russia,/Actual directions of scientific thought: problems and prospects, 263-271 (2019)

5. N. Komninos, The Age of Intelligent Cities. Smart environments and innovation-for-all strategies (Routledge, New York, USA, 2015) DOI: 10.1007/3-540-46422-0

6. V. V. Matveev, L. V. Mazur, Model of regional innovative anti-crisis programs in the conditions of geopolitical instability, Finance: theory and practice, 3 (2016) URL: cyberleninka.ru/article/n/model-regionalnyh-innovatsionnyh-antikrizisnyh-programm-vusloviyah-geopoliticheskoy-nestabilnosti (last accessed: 24.03.2021)

7. I. Mihus et al., Monitoring the state anti-crisis management of economic security of the Ukraine banking institutions, Business: Theory and Practice, 2, 21, 804-812 (2020) DOI: $10.3846 /$ btp.2020.12985

8. J. Shaw, M. Graham, Our Digital Rights to the City Meatspace Press, Maidenhead, 36, 2017) 
9. A. Vanolo, Smart mentality: The smart city as disciplinary strategy, Urban Studies, 51, 5, 883-898 DOI: $10.1177 / 0042098013494427$

10. B. Phoonsap, National economic interests'transformation in the context of national economic security prioritization, Actual Economy: local solutions for global challenges 273-275 (2019)

11. Ranking of European medium-sized cities [Electronic resource]. European Smart Cities, Electronic data, Wien (2018) URL: www.smart-cities.eu/download/smart_cities final_report.pdf (last accessed: 08.04.2018)

12. J. Samuel, A Smarter Planet: The Next Leadership Agenda [Electronic resource], URL: www.ibm.com/ibm/cioleadershipexchange/us/en/pdfs/SJP_Smarter_Planet.pdf (last accessed: 08.02.2018)

13. N. N. Yashalova, T. K. Molchanova, D. A. Ruban, Development potential of singleindustry towns in Russia: the factor of activity of regional innovation systems, /Russian Economic Online Magazine, 3, 70 (2018)

14. A. A. Sozinova, O. V. Fokina, L. A. Fufacheva, Reorganization of entrepreneurial structures within global crisis management: Problems and perspectives, Overcoming Uncertainty of Institutional Environment as a Tool of Global Crisis Management, Springer, Cham, 3-8 (2017)

15. M. L. Alpidovskaya, A. A. Svitich, National economic interests as a priority in the program of modernization of the national economy, National interests: priorities and security, 20 (2011)

16. V. V. Melnikov, Institutional problems of the development of single-industry towns in Russia (381, 2019)

17. V. N. Pavlov, Ekonomicheskie interesy: vidy, soderzhanie, otnosheniya, balansy [Economic interests: types, content, relations, balance], 1-3 (2007) URL: cyberleninka.ru/article/n/ekonomicheskie-interesy-vidy-soderzhanie-otnosheniya-balans (last accessed: 24.03.2021)

18. V. Zhdanov, The problem of economic development of the Kaliningrad region as an exclusive region of Russia, URL: www.iep.ru/files/text/cepra/kaliningrad.pdf (last accessed: 25.04.2021)

19. D. S. Rybchinsky, Modern applied models of state anti-crisis management, Bulletin of Eurasian Science, 1 (38) (2017) URL: cyberleninka.ru/article/n/sovremennyeprimenyaemye-modeli-gosudarstvennogo-antikrizisnogo-upravleniya (last accessed: 24.03.2021)

20. A. V. Filyushin, System of indicators and criteria for the effectiveness of interaction of economic systems in the region, Problems of the modern economy, 3 (2011)

21. V. V. Chernova, Implementation of regional economic interests: specifics and issues of harmonization, Bulletin of the Tambov University. Series: Humanities, 7 (2009)

22. Energy Strategy of Russia 2035 URL: www.energystrategy.ru/ab_ins/source/ES2035_09_2015.pdf (last accessed: 25.04.2021)

23. N. V. Danilova, On measures of anti-crisis management of the region and their implementation, Vestnik RUK, 2 (24) (2016) URL: cyberleninka.ru/article/n/o-merahantikrizisnogo-upravleniya-regionom-i-ih-realizatsii (last accessed: 09.08.2019)

24. O. Söderström , T. Paasche, F. Klauser, Smart Cities as corporate storytelling City, 18, 3, 307-320 (2014) DOI: 10.4324/9781315178387-20

25. Paris Agreement on Climate Change. URL: unfccc.int/files/meetings/paris_nov _2015/application/pdf/paris_agreement_russian_.pdf DOI: 10.1201/9781351116589-2 